\title{
Correction to: Spot urinary sodium in acute decompensation of advanced heart failure and dilutional hyponatremia: insights from DRAIN trial
}

\author{
Alessandro Galluzzo ${ }^{1}$ (D) Simone Frea ${ }^{1} \cdot$ Paolo Boretto $^{1} \cdot$ Stefano Pidello $^{1} \cdot$ Alessandra Volpe ${ }^{1}$. \\ Federico Giovanni Canavosio ${ }^{2}$. Pier Giorgio Golzio ${ }^{1}$. Serena Bergerone ${ }^{1} \cdot$ Gaetano Maria De Ferrari $^{1}$
}

Published online: 8 April 2020

(c) Springer-Verlag GmbH Germany, part of Springer Nature 2020

\section{Correction to: Clinical Research in Cardiology https://doi.org/10.1007/s00392-020-01617-w}

The original version of this article unfortunately contained a mistake. One of the references was incorrect. The correct reference is:

4. Frea S, Pidello S, Volpe A, Canavosio FG, Galluzzo A, Bovolo V, Camarda A; Golzio PG; D'Ascenzo F, Bergerone S, Rinaldi M, Gaita F (2020) Diuretic treatment in high-risk acute decompensation of advanced chronic heart failurebolus intermittent vs. continuous infusion of furosemide: a randomized controlled trial. Clin Res Cardiol 109:417-425. https://doi.org/10.1007/s00392-019-01521-y.

The original article can be found online at https://doi.org/10.1007/ s00392-020-01617-w.

Alessandro Galluzzo

alessandro.galluzzo@unito.it

1 Division of Cardiology, Cardiovascular and Thoracic Department, Città della Salute e della Scienza University Hospital of Turin, Corso Bramante 88, 10126 Torino, Italy

2 Division of Anestesiology, Città della Salute e della Scienza University Hospital of Turin, Corso Bramante 88, 10126 Torino, Italy 